\title{
BIOANALYTICAL RP-HPLC METHOD DEVELOPMENT AND VALIDATION OF CLOPIDOGREL BISULFATE IN WISTAR RAT PLASMA AND ITS APPLICATION TO PHARMACOKINETIC STUDY
}

\author{
RAMYA SRI SURA ${ }^{1 *}$, SUBRAHMANYAM CVS ${ }^{2}$, SHYAM SUNDER RACHAMALLA ${ }^{1}$
}

${ }^{1}$ Department of Pharmacy, University College of Technology, Osmania University, Hyderabad 500007, Telangana, India, ${ }^{2}$ Gokaraju Rangaraju College of Pharmacy, Osmania University, Hyderabad 500090, Telangana, India

Email: ramyasri.pharma@gmail.com

Received: 07 Oct 2021, Revised and Accepted: 17 Nov 2021

\section{ABSTRACT}

Objective: A novel, simple, precise, accurate, sensitive, and reproducible HPLC method for determining clopidogrel bisulfate in Wistar rat plasma was developed and validated.

Methods: The chromatographic separation was performed using Xterra C18 $(250 \times 4.6 \mathrm{~mm}, 5 \mu)$ column. Mobile phase composed of Acetonitrile ACN: $0.05 \mathrm{M}$ potassium dihydrogen orthophosphate buffer $\mathrm{pH} 4.2$ and in the ratio of $75: 25 \% \mathrm{v} / \mathrm{v}$ at a flow rate of $1.2 \mathrm{ml} / \mathrm{min}$. Detection was carried out using a PDA detector at $220 \mathrm{~nm}$. The bioanalytical clopidogrel method was validated as per ICH guidelines.

Results: The selected chromatographic condition was found to efficiently separate clopidogrel bisulfate (RT-2.838 min). The calibration curve was linear over the concentration range $40-200 \mathrm{ng} / \mathrm{ml}$ in Wistar rat plasma with a correlation coefficient of 0.999 , respectively. The precision study revealed that the cumulative percentage variation was within the acceptable limit, and accuracy research showed the value of mean percent recovery between $99.72-99.83 \%$.

Conclusion: A simple, rapid, specific, accurate, and precise analytical method was developed and validated using Wistar rat plasma. The technique was strictly validated according to the ICH guidelines. Acquired results demonstrate that the proposed strategy can be effortlessly and advantageously applied for routine analysis of clopidogrel in the Wistar rat plasma.

Keywords: RP-HPLC, Bioanalytical method, Clopidogrel bisulfate, Wistar rat plasma

(C) 2022 The Authors. Published by Innovare Academic Sciences Pvt Ltd. This is an open-access article under the CC BY license (https://creativecommons.org/licenses/by/4.0/) DOI: https://dx.doi.org/10.22159/ijap.2022v14i1.43328. Journal homepage: https://innovareacademics.in/journals/index.php/ijap

\section{INTRODUCTION}

Bioanalysis is the approach used to determine the concentration of drugs and metabolites in the biological matrices like plasma, serum, cerebrospinal fluid, urine, saliva, etc. [1]. Bioanalytical methods are essential for bioavailability and bioequivalence studies [2]. Bioanalytical method and validation are utilized to build up that a quantitative analytical approach can be connected for the biochemical process [1, 3]. Validation involves laboratory investigations that the method is suitable and reliable for the intended applications [4]. It is utilized to assess bioavailability and bioequivalence studies, quantitative evaluation of drug and metabolites, new drug development, clinical pharmacokinetics, research process, and therapeutic drug monitoring. Bioanalytical techniques are persistently undergoing changes and improvements that are the cutting edge of technology [5].

Platelets play a vital role in the hemostasis and wound-healing processes [6]. However, their hyperactivity is involved in the development and complications of several cardiovascular diseases, including thrombosis, atherosclerosis, myocardial infarction, peripheral artery disease, and ischemic stroke. Furthermore, excessive platelet activation is endorsed by the high mechanical shear forces in the circulation and vascular damage [7]. Indeed, following blood vessel injury and atherosclerotic plaque erosion, platelets adhere by their surface receptors to the subendothelial matrix, which triggers their activation and subsequent aggregation $[8,9]$. Activated platelets release prothrombotic mediators retained within their granules like adenosine diphosphate (ADP), serotonin, P-selectin, fibrinogen, Ca2+, and thromboxane A2 (TXA2), which further amplify platelet activation and thrombus formation $[9,10]$. The presence of a thrombus in an artery providing blood to a vital organ such as the heart or brain is the most common cause of acute coronary disorders, including myocardial infarction and angina [11]. Thus, the prevention of arterial thrombotic diseases has a high priority in developed countries. In this sense, the inhibition of platelet aggregation can protect against cardiovascular diseases that affect millions of people worldwide. A series of antiplatelet drugs have been used clinically to treat and prevent coronary syndromes and stroke, such as aspirin, clopidogrel [12].

Clopidogrel bisulfate is a weak base, a second-generation thienopyridine that is known chemically as Methyl (S)- $\alpha$ (2chlorophenyl)-6,7di-hydrothieno[3,2-c] pyridine-5(4H)-acetate sulfate. Clopidogrel is a potent antiplatelet agent widely used to prevent coronary artery diseases and treat vascular thrombosis [13, 14]. Its antiplatelet activity results from selective inhibition of ADP binding to the platelet receptor preventing ADP-mediated platelet responses $[15,16]$. Therefore, Clopidogrel should be used with caution in patients receiving other drugs that increase bleeding risk include anticoagulants, other antiplatelet, and NSAIDs [17].<smiles>COC(=O)[C@@H](c1ccccc1Cl)N1CCc2sccc2C1</smiles>

Fig. 1: Chemical structure of clopidogrel bisulfate [17]

Drug literature review discloses that only a few analytical quantification methods for the clopidogrel bisulfate in bulk, formulations, and biological matrices either individually or in combination with other drugs. The reported analytical techniques were UV [18, 19], HPLC [17], LC-MS/MS [20] and Liquid chromatography-tandem mass spectrometry [21]. The goal of the research was to develop a fast and empathetic bioanalytical HPLC technique for the quantitation of clopidogrel bisulfate 
in plasma samples and the application of ICH regulatory guidelines for method validation.

\section{MATERIALS AND METHODS}

\section{Chemicals and reagents}

Clopidogrel bisulfate was kindly provided as a gift sample by Lantech Pharmaceuticals Ltd, Hyderabad. Analytical grade of potassium dihydrogen orthophosphate purchased from SD Fine-Chem Limited, Mumbai, and HPLC grade of methanol and acetonitrile purchased from Merck Specialties Private Limited, India. Analytical grade orthophosphoric acid purchased from Rankem Ltd., India.

\section{Instrumentation}

Chromatographic separation of the clopidogrel bisulfate was performed on Waters HPLC Alliance 2695 separation module with autosampler equipped with Empower 2 software with PDA detector 996 model. Separation was attained using the Xterra C18 column. Electronic balance was used for weighing. The ultracentrifuge (Remi C24BL), cyclomixer (Remi CM 101) were used for sample preparation.

\section{Liquid chromatographic conditions}

Chromatographic separation was carried out using Xterra C18 (250 $\mathrm{mm} \times 4.6 \mathrm{~mm}$ ), $5 \mu \mathrm{m}$ with a mobile phase composed of Acetonitrile: $0.05 \mathrm{M}$ potassium dihydrogen orthophosphate buffer in 75:25 ratio, $\mathrm{pH}$ 4.2. The analyte was monitored with a PDA detector at $220 \mathrm{~nm}$, and samples of $10 \mu \mathrm{l}$ were injected into the HPLC system. The mobile phase was acetonitrile and $0.05 \mathrm{M}$ potassium dihydrogen orthophosphate buffer $\mathrm{pH} 4.2$ in the ratio of $75: 25(\mathrm{v} / \mathrm{v})$ at a flow rate of $1.2 \mathrm{ml} / \mathrm{min}$. The mobile phase wasfiltered through $0.45 \mu \mathrm{m}$ filter (Sartorius, Germany) and degassed for $10 \mathrm{~min}$ by sonication.

\section{Preparation of stock and standard working solutions}

All standard stock solutions and working standard solutions were prepared in a volumetric flask. First, $100 \mathrm{mg}$ clopidogrel was dissolved in the mobile phase to give $100 \mathrm{mg} / \mathrm{ml}$. standard stock solution. Next, the working standard solutions were prepared by further serial dilution from the stock solutions with mobile phase mixture. Calibration standards of 40, 80,120,160, and $200 \mathrm{ng} / \mathrm{ml}$ in control Wistar rat plasma samples were prepared by mixing with 10 $\mu \mathrm{l}$ of working stock solutions of clopidogrel. All solutions were stored in amber-colored bottles at $-4{ }^{\circ} \mathrm{C}$ prior to use.

\section{Sample preparation}

Frozen rat plasma samples were obtained from the National Institute of Nutrition, Hyderabad, thawed and allowed to reach room temperature. An aliquot of $200 \mu \mathrm{l}$ of Wistar rat plasma sample. Subsequently, the sample was extracted with $1.5 \mathrm{ml}$ of tertiary-butyl methyl ether (TBME). The mixture was vortexed for $15 \mathrm{~min}$ and centrifuged at 3,000 rpm for $10 \mathrm{~min}$. After centrifugation, the organic phase was transferred to glass tubes and evaporated to dryness using TurboVap LV Evaporator at $50{ }^{\circ} \mathrm{C}$ under a stream of nitrogen for 5 $\min$. The residue that remained after drying was reconstituted with $150 \mu \mathrm{l}$ of mobile phase mixture and vortexed for $1 \mathrm{~min}$. Then, a volume of $10 \mu \mathrm{l}$ was injected into the HPLC system [22].

\section{Method validation}

Validation of the developed method was carried out as per ICH guidelines for specificity, linearity, accuracy, precision, LOD, LOQ, and ruggedness [23].

\section{Specificity}

Specificity evaluation was carried out by screening six different sources of blank Wistar rat plasma. Samples were processed and injected into the HPLC to assess the extent to which endogenous constituents might interfere with the retention time of clopidogrel. If there is any interfering peak present at the retention time of the drug, then its response should be less than $20 \%$ of the mean response of six extracted Wistar rat plasma samples [24].

\section{Linearity}

Plasma sample's linearity was quantified using the peak-area ratio versus analyte nominal concentration [25]. For the establishment of the linearity range of the proposed method, calibration curves in plasma were prepared in the concentration range of $40-200 \mathrm{ng} / \mathrm{ml}$.

\section{Accuracy}

Acquisition studies were conducted using the standard addition method wherein a known amount of clopidogrel was added to the pre-analyzed samples according to 80,100 , and $120 \%$ levels of labeled claim further subjected to the contemplated analytical process. The percent recovery and relative standard deviation (\% RSD) were calculated for each concentration. Accuracy was calculated using the formula $\% \mathrm{RE}=(\mathrm{E}-$ T) $(100 / \mathrm{T})$, where $E$ is the experimentally determined concentration, and $T$ is the theoretical concentration [26].

\section{Recovery}

The recovery studies were carried out in Wistar rat plasma. The percentage recovery was determined using accuracy samples at $80 \%, 100 \%$, and $120 \%$ concentrations of 96,120 , and $144 \mathrm{ng} / \mathrm{ml}$ and at one concentration injection volume $(10 \mu \mathrm{g} / \mathrm{ml})$. Recovery was calculated by comparing the mean peak area of three replicates $(n=3)$ of extracted samples with the mean peak area obtained for the quality control samples of unextracted standards.

\section{Precision}

The precision was established using quality control samples $(n=3)$ at low, medium, and high clopidogrel concentrations of 40,120 , and $200 \mathrm{ng} / \mathrm{ml}$ in Wistar rat plasma [27]. The assay precision was assessed by calculating inter-and intra-day variability of quality control samples. Inter-day data was obtained by analyzing the quality control samples on three consecutive days of an assay, while intra-day precision data were obtained by analyzing three sets of quality control samples in a single day. The assay precision was calculated using the formula

$\% \operatorname{RSD}=\left(\frac{S D}{M}\right) * 100$, where $M$ is the mean of the experimentally determined concentrations and SD is the standard deviation of $M$.

\section{Robustness}

The robustness of the developed method was studied by evaluating the effect of slight but deliberate variations in chromatographic conditions. The parameters studied were flow rate and mobile phase composition [28].

\section{Ruggedness}

The ruggedness of the method was studied by changing the experimental condition with precision and accurate batch [25]. Ruggedness was performed by using different analysts [29] in the same laboratory.

\section{Limits of detection (LOD) and limit of quantitation (LOQ)}

LOD and LOQ of the developed method were estimated on the based on standard deviation and slope of the calibration curve as $3.3 \delta / \mathrm{m}$ and 10 $\delta / \mathrm{m}$, respectively. Here, $\delta$ was the regression standard deviation of intercept, and $\mathrm{m}$ was the slope of the calibration curve [30].

\section{Pharmacokinetic studies}

The applicability of the developed HPLC method for clopidogrel in rat plasma was demonstrated by the results obtained from pharmacokinetic studies conducted on male Wistar rats $(n=6)$. Male Wistar rats, weighing approximately 160-180 g, were purchased from Sainath Agencies, Musheerabad, Hyderabad, India, and Rats housed in cages were kept in a room under controlled temperature $\left(20-22^{\circ} \mathrm{C}\right.$ ) and $12 \mathrm{~h}$ day-night cycle. After $1 \mathrm{w}$ of acclimatization with free access to water and food, animals were used for the study. The animal study protocol was reviewed and approved by the Institutional Animal Ethics Committee (1757/PO/RcBiBt/S/14/CPCSEA). Each rat was treated with oral pure clopidogrel suspension at a dose of $7.70 \mathrm{mg} / \mathrm{kg}$ in a single dose and was administered by oral route with a gastric catheter or oral gavages, feeding needle [31]. Serial blood samples $(2 \mathrm{ml})$ were collected from retro-orbital venous plexus with a hematocrit over a period of $24 \mathrm{~h}$ (four biological half-lives). Rats were further divided into two subgroups $(n=3)$ for convenient blood sampling over entire study periods. 
Blood samples from each group were collected at predetermined time intervals alternatively from each subgroup into heparinized plastic tubes. All these whole blood samples were kept in cold refrigerated conditions $\left(2-8^{\circ} \mathrm{C}\right)$ until the separation of plasma. Each sample was processed further by the method mentioned under sample preparation and subjected to HPLC analysis to estimate drug content by a previously validated bioanalytical method [30]. The pharmacokinetic calculations were performed on the basis of plasma concentration-time data using PK solver add-in in MS-Excel 2007 [32].

\section{RESULTS AND DISCUSSION}

\section{Method development}

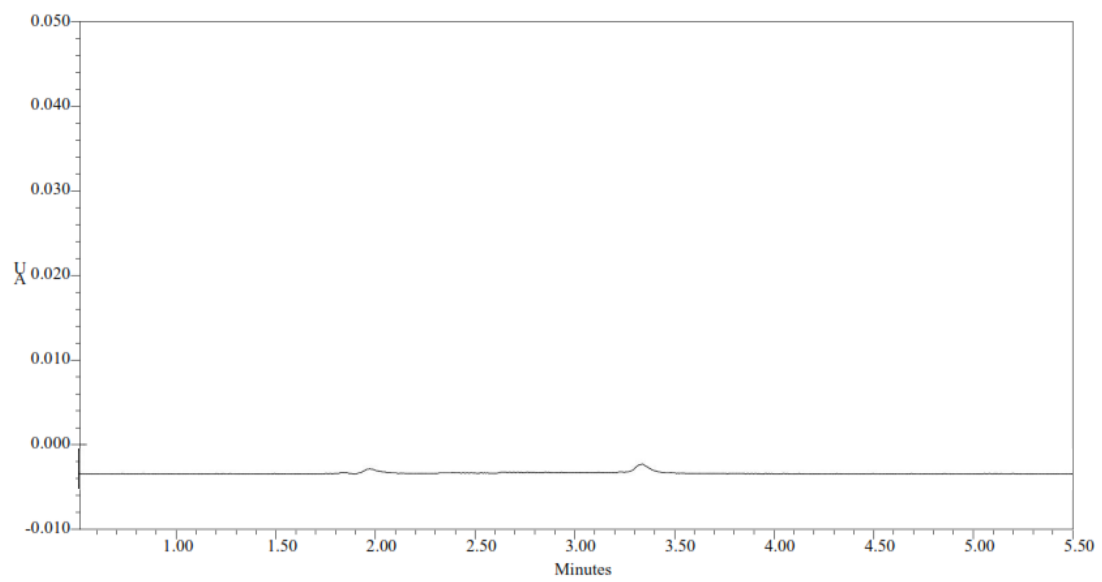

Fig. 2: Representative chromatogram of blank Wistar rat plasma

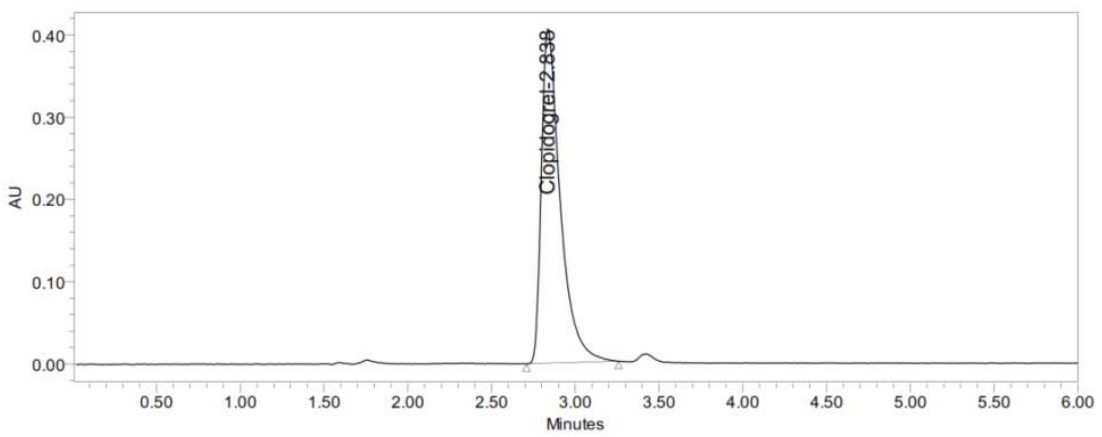

Fig. 3: Typical chromatogram of clopidogrel

Since clopidogrel is a poorly water-soluble and highly lipophilic compound, it was necessary for the method development to optimize parameters such as choice of organic solvent, $\mathrm{pH}$, the composition of mobile phase,flow rate, and oven temperature. The optimum wavelength for detecting Clopidogrel with adequate sensitivity was found to be $220 \mathrm{~nm}$. Potassium dihydrogen orthophosphate buffer and acetonitrile at $0.05 \mathrm{M}$ were again selected for the separation studies. At $\mathrm{pH} 4.2$, clopidogrel was resolved with good peak shape, but at $\mathrm{pH}>4.2$, peak tailing of clopidogrel was observed. Hence Potassium dihydrogen orthophosphate buffer (0.05 M; pH 4.2) and acetonitrile were selected for the initial separation studies.

Experiments were carried out with different compositions of acetonitrile in the mobile phase for better resolution of clopidogrel. The amount of organic content in the mobile phase fsicgntly altered the retention time of clopidogrel because of the poor aqueous solubility. The best peak shape was observed with the mobile phase consisting of ACN: $0.05 \mathrm{M}$ potassium dihydrogen orthophosphate buffer $\mathrm{pH} 4.2$ and in the ratio of 75:25 (v/v); slight changes in the mobile phase composition were observed to cause subtle differences in the retention time of clopidogrel without altering its peak response.

The effect of flow rate with optimized mobile phase composition was studied at $1.0,1.2$, and $1.4 \mathrm{ml} / \mathrm{min}$. When the flow rate increased, there was a decrease in the peak width of clopidogrel, but at flow rates of 1.2 and $1.4 \mathrm{ml} / \mathrm{min}$, there was no significant decrease in the peak width. Hence a flow rate of $1.2 \mathrm{ml} / \mathrm{min}$ was selected as the optimum flow rate since it yielded good peak shapes without endogenous peak interference at the retention time of analyte. Experiments were also performed with $\mathrm{C}_{4}, \mathrm{C}_{8}$, and $\mathrm{C}_{18}$ columns. $\mathrm{C}_{4}$ and $\mathrm{C}_{8}$ columns were unable to resolve clopidogrel from endogenous compounds. However, the $\mathrm{C}_{18}$ column analyte was determined from endogenous compounds with good peak symmetry and reproducibility.

The effect of column temperature was studied at room temperature and elevated temperatures. There was no sigrficant effect on the peak width clopidogrel, but an increase in oven temperature caused a decrease in the peak width of clopidogrel. Thus Ambient $25{ }^{\circ} \mathrm{C}$ (Room Temperature) was selected as the optimized oven temperature with the optimized chromatographic condition. The average retention time for clopidogrel was $2.838 \mathrm{~min}$.

\section{Specificity}

Specificity was evaluated using six different blank Wistar rat plasma samples. Chromatograms obtained from Wistar rat plasma samples are shown in fig. 2,3. There were no interfering peaks of endogenous compounds observed at the retention time of clopidogrel. The analyte were eluted at $2.838 \mathrm{~min}$ for clopidogrel. However, sample runtime was optimized to $6 \mathrm{~min}$. 
Table 1: Summary of chromatographic conditions

\begin{tabular}{ll}
\hline Parameters & Description \\
\hline Equipment & High-performance liquid chromatography WATERS Alliance 2695 separation module equipped with 996 PDA \\
detector, with Empower 2 software \\
Column & Xterra C18, $250 \mathrm{~mm} \times 4.6 \mathrm{~mm}, 5 \mu \mathrm{m}$ (particle size) \\
Mobile phase & ACN: $0.05 \mathrm{M}$ potassium dihydrogen orthophosphate buffer pH 4.2 and in the ratio of $75: 25$ \\
pH & 4.2 \\
Flow rate & $1.2 \mathrm{ml} / \mathrm{min}$ \\
Column and sample temperature & Ambient $25^{\circ} \mathrm{C} /$ Room Temperature \\
Detection wavelength & $220 \mathrm{~nm}$ \\
Injection volume & $10 \mu \mathrm{l}$ \\
Run time & $6 \mathrm{~min}$ \\
Retention time & $2.838 \mathrm{~min}$ \\
\hline
\end{tabular}

\section{Linearity}

A five-point linearity curve was constructed for clopidogrel Samples were quantfied using the peak area of clopidogrel. Standard calibration curves were constructed by plotting the peak area of clopidogrel concentration in plasma samples. Least squares linear regression analysis $\mathrm{y}=\mathrm{mx}+\mathrm{c}$ was performed to determine slope, intercept, and coefficient of correlation.

The correlation coeficient of the calibration curves for clopidogrel was 0.999 . The mean $( \pm S D)$ slope and intercept values for the calibration curve of clopidogrel were 1039 and 1873, respectively.

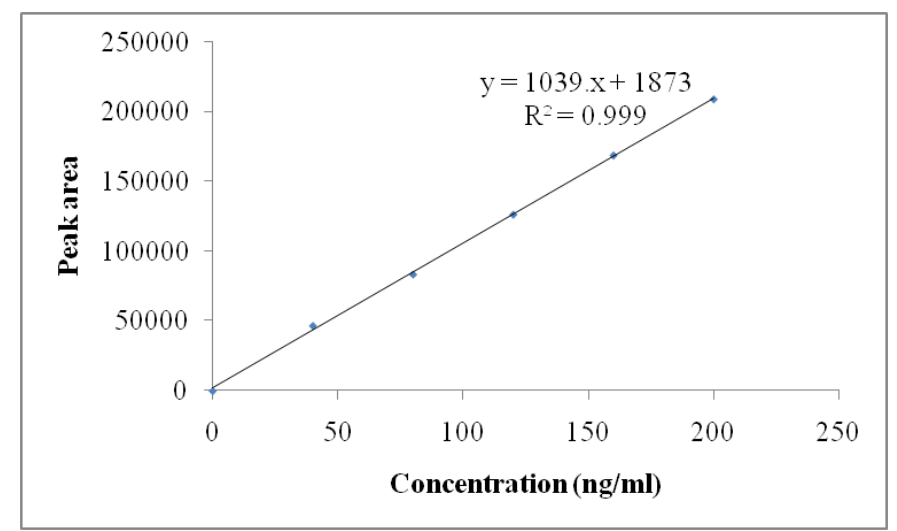

Fig. 4: Linearity curve of clopidogrel in plasma at $220 \mathrm{~nm}$ HPLC method

\section{Accuracy and precision}

The accuracy of an analytical method describes the closeness of test results to the accurate concentration of the analyte. In contrast, precision measures the degree of reproducibility of the analytical method [28, 33]. The results of intra-day and inter-day precisions are summarized in table 3 , which revealed that the developed method was accurate and precise for the quantification of clopidogrel in plasma samples.

Table 2: Accuracy of clopidogrel in plasma by HPLC method

\begin{tabular}{|c|c|c|c|c|}
\hline (\%) drug added level & Theoretical content (ng/ml) & Amount found (ng/ml) $A M \pm S D ~ n=3$ & \% Recovery & \%RSD \\
\hline 80 & 96 & $95.8 \pm 0.25$ & 99.79 & 0.26 \\
\hline 100 & 120 & $119.8 \pm 0.40$ & 99.83 & 0.33 \\
\hline 120 & 144 & $143.6 \pm 0.55$ & 99.72 & 0.38 \\
\hline
\end{tabular}

Each value represents the mean $\pm \mathrm{SD}(\mathrm{n}=3)$

Table 3: Precision of clopidogrel in Wistar rat plasma by RP HPLC method

\begin{tabular}{|c|c|c|c|c|}
\hline \multirow{2}{*}{$\begin{array}{l}\text { Concentration, } \\
\mathrm{ng} / \mathrm{ml}\end{array}$} & \multicolumn{2}{|l|}{ Intra-day } & \multicolumn{2}{|l|}{ Inter-day } \\
\hline & Concentration found $(A M \pm S D)(n=3)$ & \%RSD & Concentration found $(\mathrm{AM} \pm \mathrm{SD})(\mathrm{n}=3)$ & \%RSD \\
\hline 40 & $39.47 \pm 0.21$ & 0.55 & $39.61 \pm 0.44$ & 1.13 \\
\hline 120 & $120.36 \pm 0.22$ & 0.18 & $119.71 \pm 0.55$ & 0.46 \\
\hline 200 & $199.57 \pm 0.28$ & 0.14 & $200.03 \pm 0.72$ & 0.36 \\
\hline
\end{tabular}

Each value represents the mean $\pm S D(n=3)$

\section{Recovery}

For recovery determination, three replicates at 80,100 , and $120 \%$ quality control concentration were prepared for clopidogrel in Wistar rat plasma. The mean recovery for clopidogrel in Wistar rat plasma was 99.79\%, 99.83\%, 99.72\%, respectively.

\section{Robustness}

The low values of \%RSD for drug proposed that during all deliberate variations, assay value of test preparation was not affected, and it was by actual (table 4). Hence, the newly developed analytical method was considered to be robust. 
Table 4: Robustness of clopidogrel in plasma by HPLC method

\begin{tabular}{llll}
\hline Flow rate, $\mathbf{m l} / \mathbf{m i n}$ & \multicolumn{2}{c}{ Retention time } & \multicolumn{1}{c}{ Theoretical plates } \\
\cline { 2 - 4 } & (AM \pm SD) (n=3) & \%RSD & (AM $\mathbf{\text { SD) }}$ (n=3) \\
\hline 1.0 & $3.272 \pm 0.010$ & 0.309 & $6412 \pm 10.44$ \\
1.2 & $2.838 \pm 0.055$ & 1.938 & $6830 \pm 59.02$ \\
1.4 & $2.336 \pm 0.010$ & 0.439 & $6315 \pm 9.16$ \\
\hline
\end{tabular}

Each value represents the mean $\pm \operatorname{SD}(n=3)$

Table 5: Ruggedness of clopidogrel in plasma by RP-HPLC method

\begin{tabular}{lll}
\hline Analyst & Clopidogrel concentration, ng/ml & \%RSD \\
\hline 1 & $90.20 \pm 0.04$ & 0.049 \\
2 & $89.32 \pm 0.22$ & 0.251 \\
\hline
\end{tabular}

Each value represents the mean \pm SD $(n=3)$

\section{Ruggedness}

The ruggedness of the method was carried out by changing by a different analyst. The results are summarised in the table. The \%RSD values were less than 2 , suggesting the ruggedness of the proposed analytical method.

\section{Limits of detection (LOD) and quantitation (LOQ)}

The LOD and LOQ were observed as $1.617 \mathrm{ng} / \mathrm{ml}$ and $5.391 \mathrm{ng} / \mathrm{ml}$, respectively. These low values were indicative of the high sensitivity of the developed method.

\section{Pharmacokinetic studies}

The proposed HPLC method was successfully applied to monitor quantitatively the time course of plasma clopidogrel bisulfate concentrations after oral administration of a single $7.70 \mathrm{mg} / \mathrm{kg}$ body weight dose to adult male Wistar rats. The mean plasma drug concentration-time profile observed in these clopidogrel pharmacokinetics studies is shown in fig. 5. The values of all major pharmacokinetic parameters like maximum plasma concentration $\left(\mathrm{C}_{\max }\right)$, time required for maximum plasma concentration $\left(\mathrm{T}_{\max }\right)$, area under the curve $\left(\mathrm{AUC}_{0-24}\right)$, terminal half-life $\left(\mathrm{t}_{1 / 2}\right)$, elimination rate constant, mean residence time (MRT), clearance and volume of distribution $\left(V_{d}\right)$ have been summarized in table 5 .

\section{Table 5: Pharmacokinetic parameters of clopidogrel}

\begin{tabular}{|c|c|}
\hline Pharmacokinetic parameter & Clopidogrel pure drug \\
\hline $\mathrm{C}_{\max }(\mathrm{ng} / \mathrm{ml})$ & $85.09 \pm 2.98$ \\
\hline$t_{\max }(\mathrm{h})$ & 2 \\
\hline $\mathrm{AUC}_{0-24}(\mathrm{ng}-\mathrm{h} / \mathrm{ml})$ & $938.666 \pm 19.11$ \\
\hline Half-life $t_{1 / 2}(h)$ & $7.179 \pm 0.13$ \\
\hline Elimination rate constant $\left(\mathrm{h}^{-1}\right)$ & $0.0965 \pm 0.001$ \\
\hline $\operatorname{MRT}_{0-24}(\mathrm{~h})$ & $7.847 \pm 0.004$ \\
\hline Clearance(CL) (mL/min) & $0.0711 \pm 0.001$ \\
\hline $\mathrm{V}_{\mathrm{d}}(\mathrm{L})$ & $0.737 \pm 0.005$ \\
\hline
\end{tabular}

Each value represents the mean \pm SD $(n=6)$

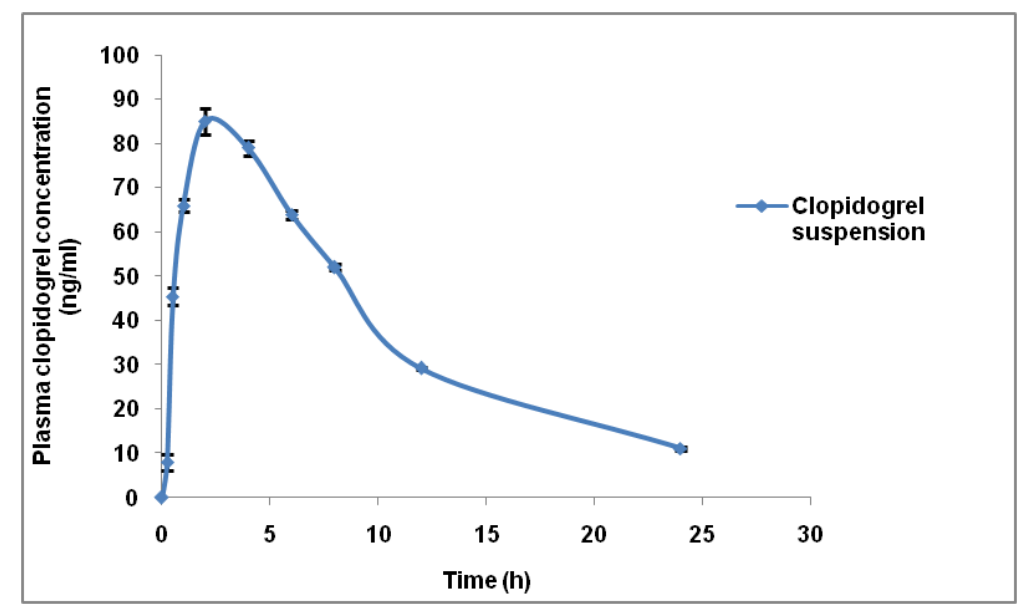

Fig. 5: Mean plasma concentration vs time profile in rats $(n=6)$

\section{CONCLUSION}

A simple, rapid, specific, sensitive, and reproducible bioanalytical HPLC method has been developed and validated for the quantitative determination of clopidogrel in small volumes of rat plasma. The method was successfully applied for studying the pharmacokinetic parameters of clopidogrel. This method can also be used for quality control tests of clopidogrel in plasma samples.

\section{ACKNOWLEDGEMENT}

The Authors are thankful to Dean and Principal, Department of Pharmacy, University College of Technology, Osmania University, for extending the support and providing research equipment and facilities to carry out the research work.

\section{FUNDING}

Nil

\section{AUTHORS CONTRIBUTIONS}

Ramya Sri Sura has generated the research plan, prepared and revised the manuscript. Subrahmanyam CVS and Shyam Sunder Rachamalla have given guidance and supervision to carry out this study. 


\section{CONFLICT OF INTERESTS}

None

\section{REFERENCES}

1. D'cruz D, Babu A, Joshy E. Bioanalytical method development and validation of ticagrelor by RP-HPLC. Int J Appl Pharm. 2017;9(3):51-4. doi: 10.22159/ijap.2017v9i3.17452.

2. Pravallika KE, Prameela RA, Kumar MR. Bioanalytical method development and validation of entrectinib in rat plasma by liquid chromatography-tandem mass spectrometry. Asian J Pharm Clin Res. 2020;13(11):155-63. doi: 10.22159/ajpcr.2020.v13i11.39005

3. Tijare LK, Nt R, Un M. A review on bioanalytical method development and validation. Asian J Pharm Clin Res. 2016;9(9);Suppl 3:6-10. doi: 10.22159/ajpcr.2016.v9s3.14321.

4. Kirthi R, Shanmugam R, Prathyusha MS, Basha DJ. A review on bioanalytical method development and validation by RP-HPLC. J Glob Trends Pharm Sci. 2014;5(4):2265-71.

5. Goel D. Ticagrelor: the first approved reversible oral antiplatelet agent. Int J Appl Basic Med Res. 2013;3(1):19-21. doi: 10.4103/2229-516X.112234, PMID 23776835.

6. Nurden AT, Nurden P, Sanchez M, Andia I, Anitua E. Platelets and wound healing. Front Biosci. 2008;13(9):3532-48. doi: 10.2741/2947, PMID 18508453.

7. Hernandez Hernandez R, Carvajal AR, Guerrero Pajuelo J, Armas de Hernandez MJ, Armas Padilla MC, Barragan 0, Boada Boada JJ, Roa E. The effect of doxazosin on platelet aggregation in normotensive subjects and patients with hypertension: an in vitro study. Am Heart J. 1991;121(1):389-94. doi: 10.1016/0002-8703(91)90877-K.

8. Davi G, Patrono C. Platelet activation and atherothrombosis. N Engl J Med. 2007;357(24):2482-94. doi: 10.1056/NEJMra071014, PMID 18077812.

9. Watson SP, Auger JM, McCarty OJ, Pearce AC. GPVI and integrin alphaIIb beta3 signaling in platelets. J Thromb Haemost. 2005;3(8):1752-62. doi: 10.1111/j.1538-7836.2005.01429.x, PMID 16102042.

10. Namrata K, Prashant $P$, Sunil A. Role of micronutrients in heart diseases. Int J Curr Pharm Res. 2021;13(5):1-5. doi: 10.22159/ijcpr.2021v13i5.1880

11. Epstein FH, Fuster V, Badimon L, Badimon JJ, Chesebro JH. The pathogenesis of coronary artery disease and the acute coronary syndromes. N Engl J Med. 1992;326(4):242-50. doi: 10.1056/NEJM199201233260406.

12. El Haouari M, Rosado JA. Medicinal plants with antiplatelet activity. Phytother Res. 2016;30(7):1059-71. doi: 10.1002/ptr.5619, PMID 27062716.

13. Rada FH. Antiplatelet adequacy of cyclopentyl triazolopyrimidine versus clopidogrel in-patients with coronary heart disease. Asian J Pharm Clin Res. 2018;11(12):536-9. doi: 10.22159/ajpcr.2018.v11i12.29703.

14. Mazyed EA, Zakaria S. Enhancement of dissolution characteristics of clopidogrel bisulphate by proniosomes. Int J Appl Pharm. 2019;11(2):77-85. doi: 10.22159/ijap.2019v11i2.30575.

15. Deshkar SS, Pawara AS, Shirolkar SV. Formulation and optimization of floating tablets of clopidogrel bisulfate using design of experiments. Int J Appl Pharm. 2018;10(6):94-102. doi: https://doi.org/10.22159/ijap.2018v10i6.27873

16. Shifrin MM, Widmar SB. Platelet inhibitors. Nurs Clin North Am. 2016;51(1):29-43. doi: 10.1016/j.cnur.2015.10.004, PMID 26897422.

17. Jain HK, Deore DD. Bioanalytical method development and validation for estimation of clopidogrel bisulfate in human plasma by RP-HPLC. Int J Appl Pharm. 2018;8(4):18-21. doi: https://doi.org/10.22159/ijap.2016v8i4.13521
18. Suhas G, Venkatamahesh R. Development and validation of a derivative UV-spectrophotometric method for quantitative estimation of clopidogrel bisulfate in bulk and pharmaceutical dosage form. Int J Chem Res. 2012;4:497-501.

19. Patil L, Gudi V, Jadhav D, Kadam Y, Dalvi D. Development and validation of a UV-spectrophotometric method for simultaneous estimation of amlodipine besylate and clopidogrel bisulfate in bulk and tablet dosage form. Scholars Res Library 2013;5:282-7.

20. Venkanna B, Shreedhara C, Ajitha M. Rapid and rugged bioanalytical method development and validation clopidogrel in human plasma using liquid chromatography/tandem mass spectroscopy. Am J PharmTech Res. 2011;1(2):66-80.

21. Harahap Y, Maysyarah I. Analytical validation of clopidogrel in human plasma through ultrahigh performance liquid chromatography-tandem mass spectrometry. Int J Appl Pharm. 2017;9;Suppl 1:163-7. doi: 10.22159/ijap.2017.v9s1.79_86.

22. Reddy BKK, Sekhar KBC, Mohan CK. Bioanalytical method development and validation for the simultaneous determination of vildagliptin and telmisartan in rabbit plasma using RP-HPLC. J Pharm Res Int. 2021;33(1):76-86. doi: 10.9734/jpri/2021/v33i131141.

23. Tijare LK, Nt R, Un M. A review on bioanalytical method development and validation. Asian J Pharm Clin Res. 2016;9(9);Suppl 3:6-10. doi: 10.22159/ajpcr.2016.v9s3.14321.

24. Sandhya P, Subrahmanyam CVS, Patnaik KR. Bioanalytical method development and validation of valsartan in rabbit plasma. Int J Pharm. 2015;5(4):1360-4.

25. Kumar SS, Muruganantham V. A simple and rugged bioanalytical method development and validation of Brivudine in human plasma by using high-performance liquid chromatography. Int J Pharm Pharm Sci. 2020;12(7):45-50. doi: https://doi.org/10.22159/ijpps.2020v12i7.37703

26. Venkatesh G, Majid MI, Ramanathan S, Mansor SM, Nair NK, Croft SL, Navaratnam V. Optimization and validation of RPHPLC-UV method with solid-phase extraction for determination of Buparvaquone in human and rabbit plasma: application to pharmacokinetic study. Biomed Chromatogr. 2008;22(5):535-41. doi: 10.1002/bmc.965, PMID 18205140.

27. Kalshetti MS, Patil RY, Karale RA, Kulkarni AA. Bioanalytical method development for estimation of deferasirox in human plasma. Int J Pharm Pharm Sci. 2015;7(9):399-402.

28. Patel D, Sawant KK. Oral bioavailability enhancement of acyclovir by self-micro emulsifying drug delivery systems (SMEDDS). Drug Dev Ind Pharm. 2007;33(12):1318-26. doi: 10.1080/03639040701385527, PMID 18097805.

29. Madhavi S, Rani AP. Bioanalytical method development and validation for the determination of sofosbuvir from human plasma. Int J Pharm Pharm Sci. 2017;9(3):35-41. doi: 10.22159/ijpps.2017v9i3.16185.

30. Patel JM, Dhingani AP, Garala KC, Raval MK, Sheth NR. Development and validation of bioanalytical HPLC method for estimation of telmisartan in rat plasma: application to pharmacokinetic studies. Dhaka Univ J Pharm Sci. 2012;11(2):121-7. doi: 10.3329/dujps.v11i2.14562.

31. FDA guidance for industry: bioanalytical method validation. United States Department of Health and Human Services, Food and Drug Administration, Center for Drug Evaluation and Research; 2001.

32. Zhang Y, Huo M, Zhou J, Xie S. PK solver: an add-in program for pharmacokinetic and pharmacodynamic data analysis in microsoft excel. Comput Methods Programs Biomed. 2010;99(3):306-14. doi: 10.1016/j.cmpb.2010.01.007, PMID 20176408.

33. ICH Harmonized tripartite guideline validation of analytical procedures: text and methodology;Q2: (R1), Parent Guidelines; 1994. 